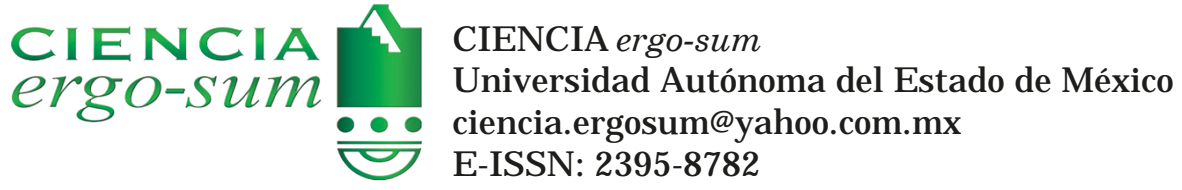

\title{
Variación de la calidad del agua de La Ciénega de Tláhuac, México
}

De la Lanza Espino, Guadalupe; Hernández Pulido, Salvador

Variación de la calidad del agua de La Ciénega de Tláhuac, México CIENCIA ergo-sum, vol. 26, núm. 3, noviembre 2019-febrero 2020| e61

Universidad Autónoma del Estado de México, México

Esta obra está bajo una Licencia Creative Commons Atribución-NoComercial-SinDerivar 4.0 Internacional.

Dela Lanza Espino, G. y Hernández Pulido, S. (2019). Variación de la calidad del agua de La Ciénega deTláhuac, México. CIE NCIA ergo-sum, 26(3). https://doi.org/10.30878/ces.v26n3a4 


\title{
Variación de la calidad del agua de La Ciénega de Tláhuac, México
}

Water quality variation of Cienega de Tlahuac, Mexico

Guadalupe de la Lanza Espino

Universidad Nacional Autónoma de México, México

gdlle@unam.mx

Recepción: 11 de diciembre de 2017

Aprobación: 31 de mayo de 2018

Salvador Hernández Pulido

Universidad Nacional Autónoma de México, México

fshp@ib.unam.mx

\section{RESUMEN}

En las márgenes de la Ciénega de Tláhuac se encuentran actualmente asentamientos humanos y se desarrollan actividades agropecuarias que impactan el medio acuático por las descargas de aguas residuales. Debido a ello, este trabajo evalúa la calidad del agua y la compara con información publicada hace 20 años. Los resultados muestran alta conductividad derivada de escurrimientos agropecuarios periféricos que emplean fertilizantes, elevada dureza, altos contenidos de sulfatos, $\mathrm{pH}$ alcalino, concentración de oxígeno disuelto desde sobresaturación hasta hipoxia o anoxia, una hipereutrofización con elevados niveles de nitrógeno y fósforo totales, además de contaminación bacteriana por coliformes fecales. Los resultados encontrados son más altos comparados con los de 20 años atrás y señalan una mala calidad del agua, en particular hipereutrofizada.

Palabras ClaVe: Ciénega de Tláhuac, calidad del agua, hipereutrofización.

\begin{abstract}
At present, domestic and farming activities take place along its margins of the Cienega de Tlahuac and affect the water through runoff. In view of this, the study evaluated the water quality and compared it to data which was published 20 years ago. The results showed high conductivity due to surrounding farming runoff rich in fertilizers, hard water with a high sulfate content, an alkaline $\mathrm{pH}$, an oxygen content that varied from anoxia or hypoxia to oversaturation, a hypereutrophication due to high levels of total nitrogen and phosphorus, and contamination due to fecal coliform bacteria. These data are higher than those of 20 years ago and indicate a bad water quality, particularly hypereutrophic.

KEYWORDS: Cienega de Tlahuac, water quality, hypereutrophication.
\end{abstract}

\section{INTRODUCCIÓN}

Los ambientes acuáticos continentales experimentan modificaciones por la evolución geológica natural. Sin embargo, las actividades humanas, resultado del crecimiento demográfico y tipo de producción y explotación de recursos naturales, se traducen en un alto grado de deterioro que incluye la muerte de innumerables especies nativas o endémicas importantes ecológica y económicamente.

Las descargas de aguas residuales en los ambientes acuáticos naturales o artificiales, como las procedentes de asentamientos urbanos y agropecuarios, conllevan grandes cantidades de materiales orgánicos, fertilizantes, altas cargas de sedimentos por la deforestación que erosiona distintos tipos de suelo y rocas, además de restos de compuestos no biodegradables de origen sintético como plásticos, latas de refrescos, restos de llantas, productos derivados del petróleo, entre otras fuentes, de elevados tiempos de degradación y que son arrojados por los pobladores a los cuerpos de agua como basura (Botello y Villanueva, 2017).

Un ejemplo desafortunado de lo anterior es el de la Ciénaga de Tláhuac, cuyo nombre se debe al poblado de Tláhuac, que formaba parte central de Chalco, uno de los lagos de mayores dimensiones de la antigua Cuenca de México (Alcántara y Escalante Pliego, 2005). Actualmente la Ciénega de Tláhuac, considerada como un humedal 
Ramsar, según definición en el 2013, representa un ambiente acuático fundamental para una amplia diversidad de aves locales y migratorias, además de invertebrados (por ejemplo insectos y crustáceos), peces (charales y axolotes), anfibios y reptiles (CONABIO, 2017a). A su vez, es un cuerpo de agua eutrofizado por las descargas de los asentamientos humanos periféricos cuyas aguas residuales llevan compuestos nitrogenados y fosforados inorgánicos (Zambrano et al., 2003).

Dada la evolución geológica de la Cuenca de México antes y después del siglo XVI, se han presentado cambios morfológicos que pueden ser ejemplificados en el Lago de Chalco, que incluso influyeron en Tláhuac, los cuales han sido dinámicos hasta la actualidad. Por su parte, la UNESCO-México (2006) señala que tales cambios pueden verse como canales a las chinampas, sistema agrícola implementado entre los siglos XV y XVII, e incrementados por el crecimiento poblacional en los alrededores de la Ciénaga de Tláhuac. García Calderón y De la Lanza Espino (1995) han referido que la formación de canales fue a raíz de las necesidades antropogénicas para el manejo del agua con fines tanto para el consumo humano como para actividades económicas (pesca y fundamentalmente agricultura), que altera la fisicoquímica o calidad del agua y sus recursos naturales. Este artículo tiene como objetivo analizar las variaciones de corto plazo del agua de la Ciénega Tláhuac entre junio de 2008 y junio 2009, así como discutir sus cambios con información publicada correspondiente a diversos años.

\section{1. Área de ESTUDIO}

La Ciénega de Tláhuac, al igual que los lagos de Xochimilco, Chalco y Texcoco son parte de un remanente del antiguo lago que cubría la mayor porción de la Cuenca de México (Alcántara y Escalante Pliego, 2005). La Ciénega de Tláhuac se ubica en la planicie lacustre de Chalco, al sureste de la Ciudad de México (coordenadas centrales: $19^{\circ} 16^{\prime} 5^{\prime \prime}$ N, 98 58' 23" O) (mapa 1). Según Meléndez Herrada y Binnqüist Cervantes (1997), la zona de influencia de la ciénega abarca una superficie total de entre 1000 a 1500 ha. Se originó por una depresión topográfica resultante del bombeo de agua subterránea, realizado en 1984, del sistema de pozos Mixquic-Santa Catarina, en la cual se acumuló agua de lluvia y también por escurrimientos periféricos (Ortiz Zamora y Ortega Guerrero, 2007), aunque según otros autores su origen se remonta al siglo XII (Barreiro Güemes et al., 1997). Si se toma como base la división de la ciénega hecha por Ayala Pérez et al. (2013) en cuatro lagos (mapa 1), su profundidad varía tanto espacial como estacionalmente: en los lagos 1 y 2 el promedio es $>2 \mathrm{~m}$, pero en el 3 y 4 son más someros, pues oscilan entre 0.5 a $1.5 \mathrm{~m}$ de profundidad; en cambio, el canal puede llegar a secarse o a sobrepasar los $3 \mathrm{~m}$. Su morfometría es irregular y varía por año, además comparte límites entre el Valle de Chalco y el Estado de México. En la actualidad es un cuerpo de agua eutrofizado que se utiliza como área de descarga de aguas residuales domésticas y agropecuarias, ya que en las márgenes se han asentado poblaciones con requerimientos hídricos para diversas actividades humanas que contaminan el agua (Zambrano et al., 2009). Una consecuencia de dicha eutrofización es la disminución del oxígeno disuelto en el agua que conlleva a la hipoxia, incluso a la anoxia, y finalmente a la muerte de organismos aeróbicos.

El clima de la zona es templado subhúmedo, con temperaturas medias anuales de $16-18{ }^{\circ} \mathrm{C}$ y precipitaciones de verano (García, 1973). La temporada de lluvias va de junio a octubre y alcanza niveles máximos de agosto a octubre y la temporada de secas se extiende de noviembre a mayo. Los niveles de agua de la Ciénega de Tláhuac fluctúan de acuerdo con la precipitación que varía de 1200 a $2000 \mathrm{~mm}$ anuales (Arriaga et al., 2000).

La flora incluye tular Schoenoplectus acutus, Scirpus lacustris junco de agua, Eichornia crassipes jacinto de agua, plantas flotantes como la lentejilla de agua y chichicastle con las especies Lemna minor y Azolla microfila, Hydrocotile americana (ombligo de Venus), pastizal Distichlis spycata, Pennisetum clandestinum (pasto kikuyo), Suaeda nigra (romerillo). En los alrededores se realizan actividades agrícolas (maíz Zea mais, y frijol Phaseolus vulgaris, principalmente) y ganaderas (como cerdos Sus scrofa, vacas bos taurus, entre otros), como lo han señalado Barreiro-Güemes et al. (1997) y Barreiro Güemes (1998). Ayala Pérez et al. (2013) dividieron la Ciénega de Tlahuac en cuatro secciones o lagos para su estudio a través de dos vías 
vehiculares: la avenida Tláhuac-Chalco y un camino de terracería que delimita la Ciudad de México del Estado de México (mapa 1); a su vez, las secciones están interconectadas por tubos subterráneos y presentan diferencias en cuanto a tamaño, cobertura vegetal y actividades humanas (Meléndez Herrada y Binnqüist Cervantes, 1997). Esta división se basó en diferentes características y dimensiones que por su importancia es necesario describirlas detalladamente y se toma como base lo referido por Ayala Pérez et al. (2013). Un área de aproximadamente 61 ha, a la que denominaron laguna 1, se dividió en cuatro lagos para este estudio (mapa 1). En sus porciones norte y oeste presenta pequeños manchones tule (Scirpus lacustris), que se vuelven más densos en la porción sur y conforman una red de canales someros, a los cuales se añaden planicies lodosas y de pasto salado (Distichlis spicata). La laguna 2 presenta un espejo de agua de aproximadamente 64 ha (mapa 1) con una cubierta de vegetación emergente, sobre todo hacia sus costados oeste y este, mientras que en la parte sur las aguas son someras y continúan en planicies lodosas con parches de pasto salado. La laguna 3 tiene 196 ha y colinda con el poblado de Xico, por lo que está sometida a una fuerte presión por la actividad humana; al este recibe desechos sólidos y aguas residuales de origen urbano y en la parte noroeste hay corrales de ganado vacuno y porcino, así como ganadería extensiva en los pastizales de la parte norte; los tulares son poco abundantes y forman pequeños islotes en donde las aves suelen posarse; éstos se concentran en la periferia, principalmente al sur y oeste. La laguna 4 tiene una extensión de 101 ha, además presenta la menor superficie de tular, concentrada en la orilla sur. Lo anterior ha ocasionado, entre otros efectos, la pérdida de zonas de refugio y alimentación para aves acuáticas y la disminución de sus poblaciones (Ayala Pérez et al., 2013).

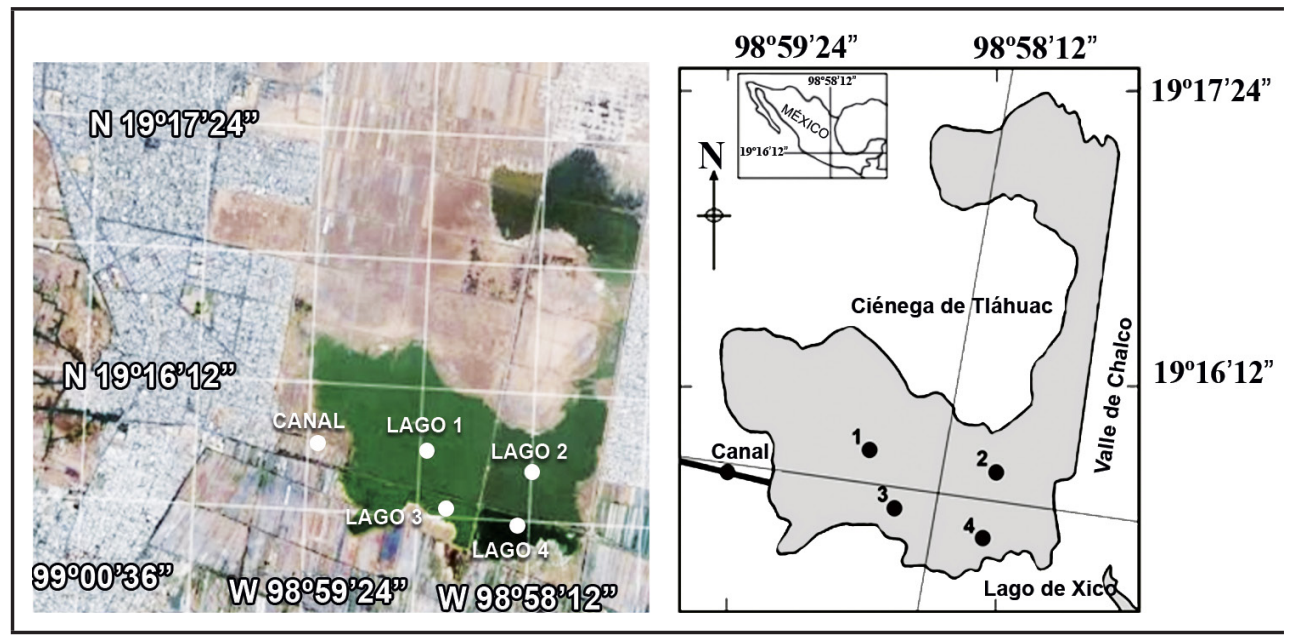

MAPA 1

Imagen satelital (Google) y la ubicación del área de estudio con las estaciones de muestreo en la Ciénega de Tláhuac

Fuente: modificado de Ayala Pérez et al., 2013.

Según la Comisión Nacional de la Biodiversidad (CONABIO, 2017b) al modificarse el entorno por desforestación, denudación y erosión de suelos, desecación de lagos, pérdida de hábitats terrestres y acuáticos, sobreexplotación y agotamiento de acuíferos y cambios en el patrón hidrológico, así como un crecimiento urbano sin planificación, han surgido transformaciones ambientales de diverso tipo, por ejemplo la reducción de la superficie de la ciénega y la profundidad del agua, donde su deterioro en la calidad influye a su vez en la flora y la fauna haciendo más deletéreas sus condiciones de sobrevivencia, entre otros factores. A lo anterior también se suma la influencia de la zona urbana-industrial con contenidos altos de metales pesados, nutrientes y materia orgánica. De acuerdo con un reporte de la Procuraduría Ambiental y de Ordenamiento Territorial 
(PAOT, 2008), en el sitio había 30 asentamientos irregulares y 10 sitios ilegales de tiro de cascajo que cubrían más de 140 ha. El cascajo ha sido usado para rellenar la ciénega y obtener terrenos para edificar viviendas ocasionando el cambio de uso de suelo y la desecación de Tláhuac. Además, hay cinco sitios de confinamiento de desechos sólidos y sitios clandestinos. Entre 50 y 55 m3/s de aguas residuales domésticas e industriales son exportadas sin tratamiento fuera de la cuenca. A pesar de ello, la Ciénaga de Tláhuac se puede considerar un humedal natural, pero modificado antropogénicamente en forma permanente dado que no se han tomado medidas para su recuperación.

La Ciénega de Tláhuac es un humedal importante para la avifauna de la región (CONABIO, 2017 b); en este cuerpo de agua aparecen durante el invierno seis especies protegidas por el gobierno mexicano; sin embargo, existen factores antrópicos que ponen en riesgo su integridad y que hacen necesarias acciones de protección y conservación. Durante la época de migración, entre los meses de octubre y marzo, la ciénega recibe un promedio de 25000 individuos de aves migratorias (Ayala Pérez et al., 2013). Cabe señalar que de las 136 especies de aves que se han registrado en la ciénega, siete están enlistadas bajo alguna categoría de riesgo en la norma mexicana de especies en peligro de extinción (NOM-059-SEMARNAT-2010), cuatro se encuentran en la Lista Roja de la Unión Internacional para la Conservación de la Naturaleza (UICN) y tres son endémicas del país, una de ellas es el pato mexicano (Anas platyrhynchos diazi), que posee una importante población. Debido a lo anterior, el humedal de Tláhuac es reconocido en el país como un Área Importante para la Conservación de las Aves (AICA) por parte de la Comisión Nacional para el Conocimiento y Uso de la Biodiversidad en conjunto con Pronatura Sur e internacionalmente Bird Life International la designó como una Área Importante de Biodiversidad de Aves, además de otorgarle un reconocimiento internacional.[1]

\section{Materiales y métodos}

Entre 2008 y 2009 se efectuaron muestreos mensuales en la parte central de cada uno de los lagos en la que está dividida la Ciénega de Tláhuac y también en un canal situado cerca de la delegación Tláhuac (mapa 1). Se determinaron in situ: temperatura, $\mathrm{pH}$, color, conductividad, oxígeno disuelto-saturación con un equipo multisensor de campo YSI 556 MPS. A media profundidad se colectaron muestras de agua con una botella Niskin, posteriormente se congelaron a $4{ }^{\circ} \mathrm{C}$ en una hielera para la cuantificación en el laboratorio y después se descongelaron hasta licuificarse. Los parámetros utilizados fueron color (escala de Forel), sulfatos, dureza (por titulación por EDTA), nutrientes (ortofosfatos-fósforo total, amonio en muestra sin filtrar para incluir a los adsorbidos y absorbidos por arcillas y que potencialmente pueden ser asimilados por el fitoplancton), demanda química de oxígeno (DQO), sustancias activas al azul de metileno (detergentes) y metales traza, determinados a través del desarrollo de color y cuantificado espectrofotométricamente con base en las técnicas de la American Public Health Association (APHA, 1995). En particular, las unidades de los nutrientes fueron expresadas en micromoles $(\mu \mathrm{M})$ para un enfoque ecológico y estimar el grado de eutrofización. En su caso, los sólidos suspendidos se evaluaron a través de una sedimentación diferencial entre el fitoplancton y los sedimentos (arcilla y arena). Los coliformes totales y fecales fueron a través de la técnica comercial de Colillert (IDEXX Laboratories, Inc).

\section{Resultados Y Discusión}

\section{1. Temperatura}

Este parámetro mostró un comportamiento estacional con los registros más bajos en los meses fríos de diciembre, enero y febrero con un intervalo entre 13 a $15^{\circ} \mathrm{C}$ y los más cálidos en julio y agosto de 24 a $19^{\circ} \mathrm{C}$. En el periodo de sequía los cuatro lagos redujeron el tirante de agua por la evaporación con un incremento en la temperatura 
(gráfica 1); oscilación semejante a la registrada por Ayala Pérez y Avilés Alatriste (1997). Esta variable se asocia con la variación climática estacional, con la dinámica de circulación y el aislamiento de los cuatro lagos.

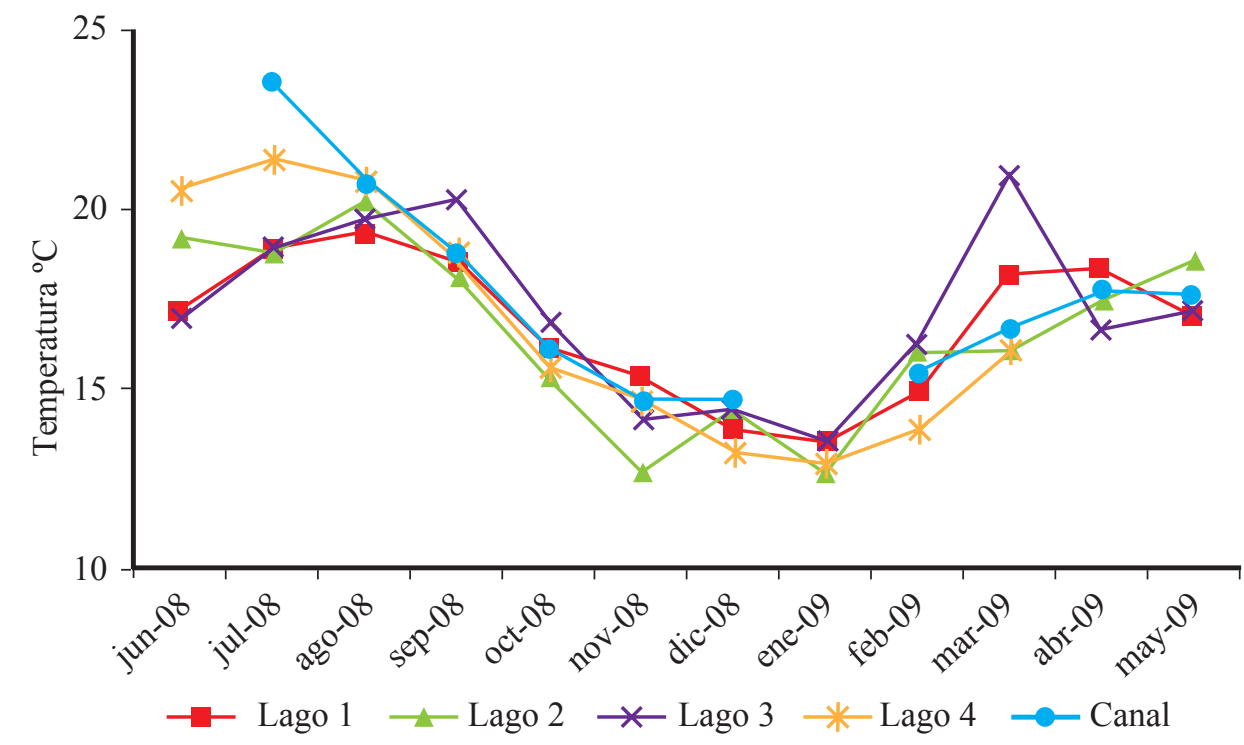

GRÁFICA 1

Variación mensual de temperatura en cuatro lagos y canal de la Ciénega de Tláhuac Fuente: elaboración propia.

\section{2. Potencial de hidrógeno $(\mathrm{pH})$}

El pH fue alcalino de 8.81 a 9.63, con una sola excepción de 6.36 a 7.3 en el canal. Estos intervalos son resultado de la presencia de los carbonatos característicos de la geología de la zona, además de las altas densidades del fitoplancton que al fotosintetizar asimilan el bióxido de carbono $\left(\mathrm{CO}_{2}\right)$ procedente de la atmósfera (efecto biológico), al mismo tiempo forma ácido carbónico $\left(\mathrm{H}_{2} \mathrm{CO}_{3}\right)$ que es inestable, desplazando la reacción hacia la formación de los bicarbonatos o carbonatos que imprimen la condición alcalina (efecto químico), como se ha visto en otros cuerpos de agua en México. Barreiro Güemes en 1997 refirió un pH para la Ciénega de Tláhuac entre 8.9 a 9.1 y Valladares Rodríguez et al. (2016) en el lago Xico, situado a pocos metros de Tláhuac, registraron un pH alcalino de 9.77; intervalos semejantes a los determinados por Zambrano et al. (2009) en Xochimilco, ya que son del mismo origen hidrológico de la Cuenca de México, similares a los humedales artificiales San Juan de Aragón y Tezozomoc ubicados en la Ciudad de México (Oliva Martínez et al., 2008; Luna Pabello y Aburto Castañeda, 2014; Nandini et al., 2016).

\subsection{Color}

Aunque un agua coloreada puede no ser perjudicial, sí presentaría ciertos inconvenientes, además de generar sospechas en su calidad convirtiéndose en un problema estético, de consumo, que resultaría en un inadecuado procedimiento en la planta de tratamiento. Al respecto, en el caso de los cuatro lagos de la Ciénaga de Tláhuac se determinaron coloraciones elevadas cercanas a las 500 unidades Pt-Co en todos los meses de muestreo; los niveles más altos se registraron en los lagos 3 y 4 (gráfica 2). Por su parte, Valladares Rodríguez et al. (2016) determinaron en el lago Xico 28 unidades $\mathrm{Pt}-\mathrm{Co}$, de condiciones aceptables para uso doméstico de acuerdo con lo propuesto en la página arturobola.tripod.com/color.htm (consultada en enero de 2017). Con base en este parámetro se considera que el valor estético y de recreación es bajo. 


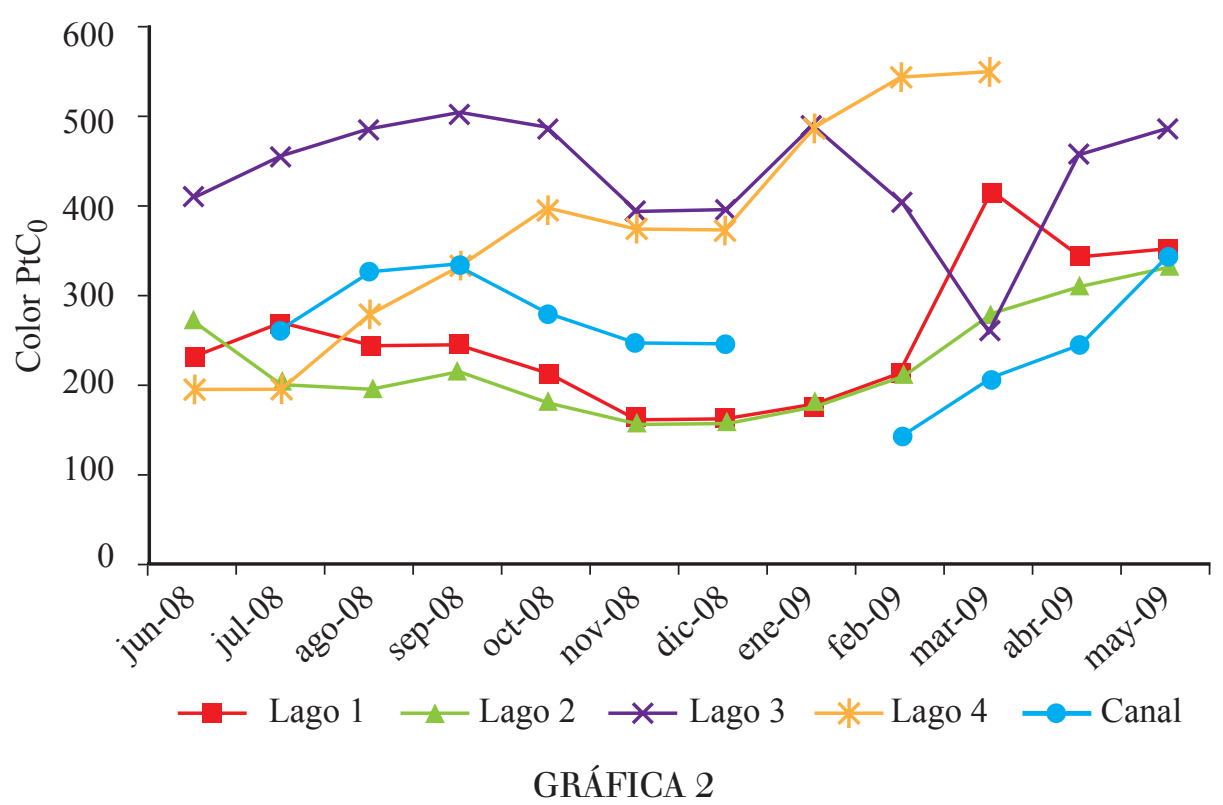

Variación mensual de color en cuatro lagos y el canal de la Ciénega de Tláhuac Fuente: elaboración propia.

\subsection{Conductividad}

La conductividad fue heterogénea espacial y temporalmente entre los cuatro lagos incluyendo el canal (gráfica 3). El lago 3 fue el más alto en todos los meses por la alta evaporación, pérdida de la superficie de las áreas periféricas y por la extracción del agua para la agricultura, de donde se estimó un intervalo de variación entre 4 y $5 \mathrm{~ms} / \mathrm{cm}$. El resto de los lagos reciben aguas residuales y de aguas tratadas de la planta de tratamiento del Cerro de la Estrella (Escobar Ruiz, 2014), por lo que la conductividad oscila temporal y espacialmente según la intermitencia del volumen descargado. Este parámetro se asocia al clima y a la ubicación de los lagos, por lo cual las diferencias no fueron significativas. La conductividad es considerada como un parámetro conservativo (no reacciona química o biológicamente), como se puede ver en la semejanza seis años después de lo registrado por Zambrano et al. (2003), con excepción del lago 3 dada la cercanía de los campos agrícolas.

\section{5. Sulfatos}

El contenido de sulfatos fue muy variable tanto espacial como temporalmente (de $<100$ a $>$ de $800 \mathrm{mg} / \mathrm{L}$ ), con los máximos entre febrero y marzo (época seca) y los mínimos entre julio y septiembre (época de lluvias); sin embargo, el lago 3 fue el que presentó los niveles más altos en todos los muestreos, le siguió el lago 2 y 4 (gráfica 4), los de menor profundidad, y que con la desecación concentran este ion; esta misma circunstancia se pudo observar en el canal. Se calculó una correlación estadística significativa $(r=0.7)$ entre sulfatos y conductividad (gráfica 5), lo que puede significar la existencia de sulfato de sodio o sulfato de calcio (con diferencias en solubilidad); en el caso de esta última sal puede utilizarse como fertilizante natural (EcuRed, 2017). Las concentraciones de sulfatos en aguas naturales son variables y en áreas que tienen altos niveles (> $300 \mathrm{mg} / \mathrm{L}$ ) pueden afectar las actividades agrícolas. En el lago de Xico Valladares Rodríguez et al. (2016) estimaron sulfatos en una concentración de $578 \mathrm{mg} / \mathrm{L}$, contenido intermedio que puede ser resultado de la época. En el caso del lago 3 también los sulfatos pueden proceder de fertilizantes (Fink, 1988), de los pesticidas 
(Martínez Vidal et al., 2004) y de los jabones (Sánchez, 2004; Sandoval et al., 2014). Este ion considerado no conservativo es reactivo químicamente, ya que tiende a formar sulfuros bajo condiciones hipóxicas o anóxicas como fue detectado en el canal; cabe señalar que tiene diferente grado de toxicidad para la biota acuática según la época, la profundidad y las descargas urbanas.

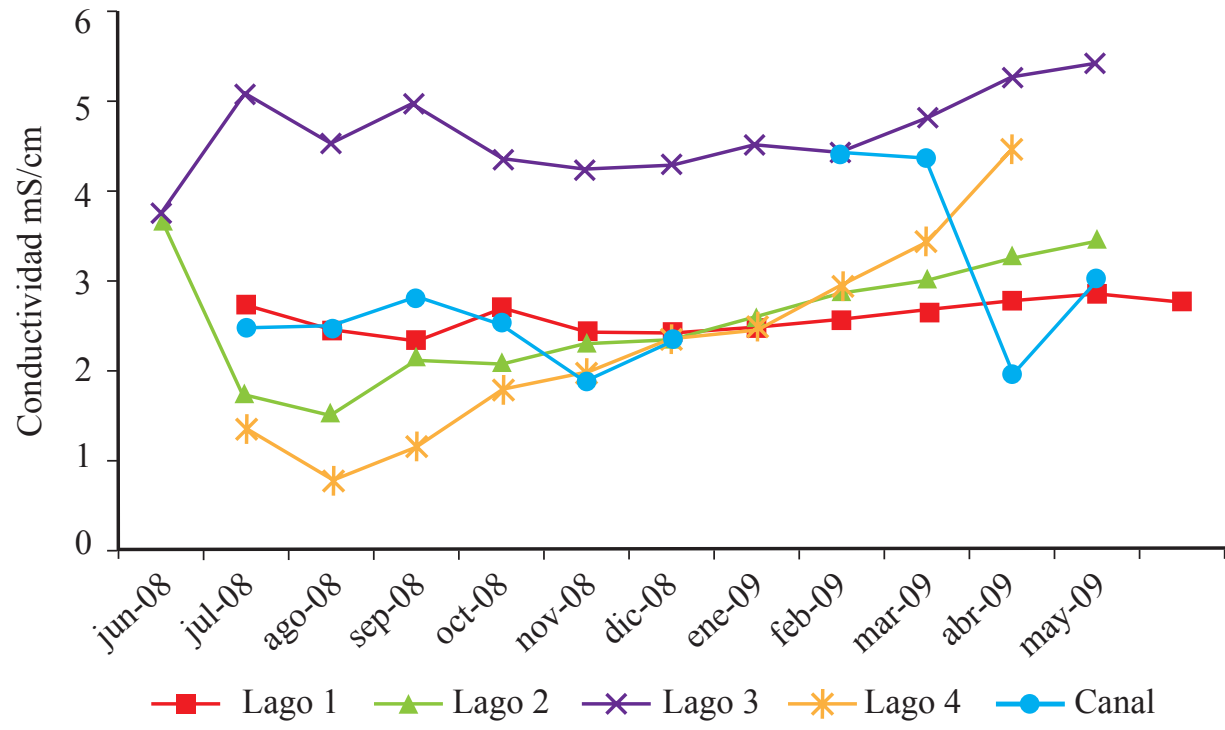

GRÁFICA 3

Variación mensual de conductividad en cuatro lagos y canal de la Ciénega de Tláhuac Fuente: elaboración propia.

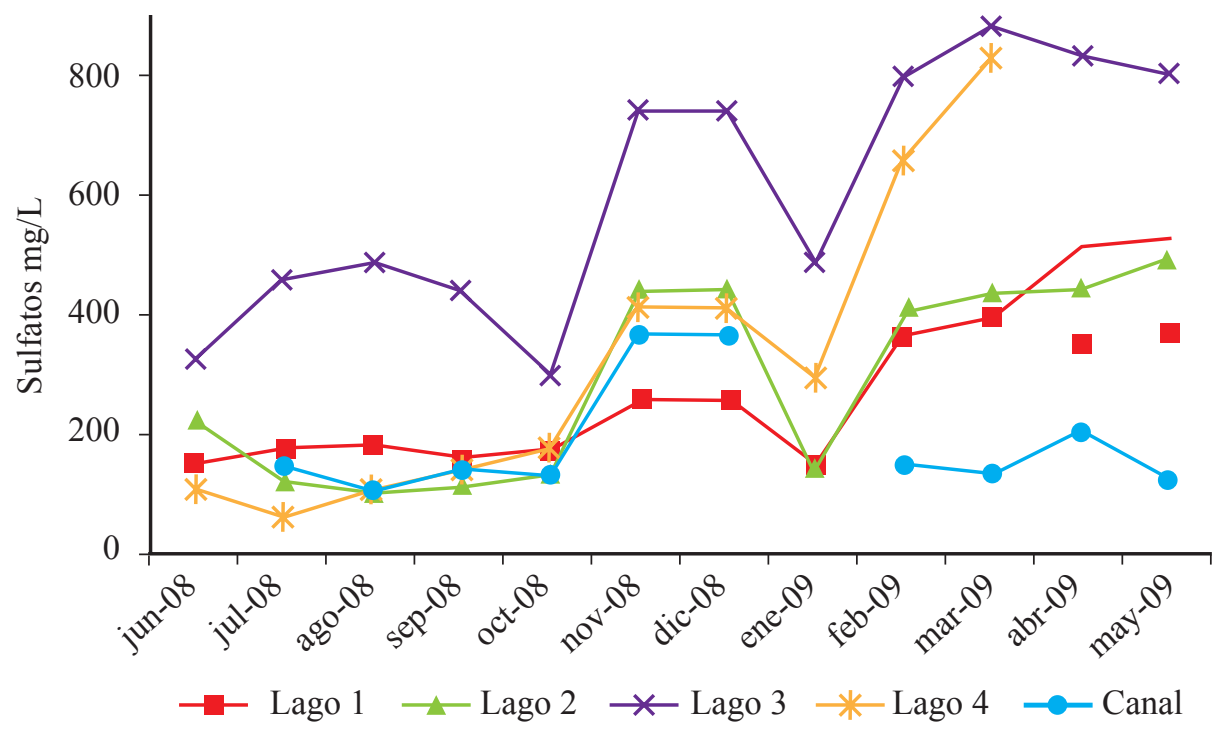

GRÁFICA 4

Variación mensual de sulfatos en cuatro lagos y del canal de la Ciénega de Tláhuac Fuente: elaboración propia. 

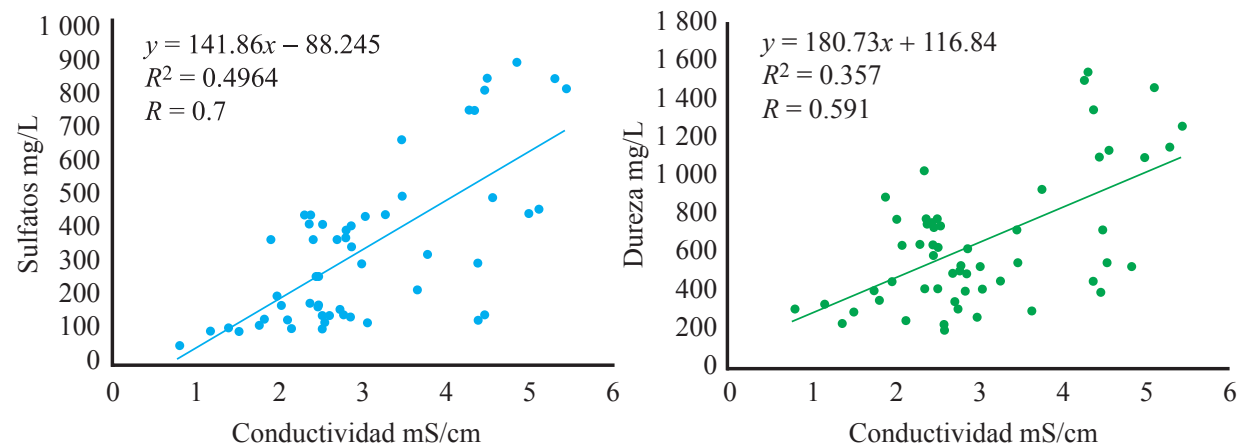

GRÁFICA 5

Correlación entre conductividad y sulfatos y dureza en cuatro lagos y del canal de la Ciénega de Tláhuac Fuente: elaboración propia.

\section{6. Dureza}

Las aguas de los cuatro lagos de la Ciénaga de Tláhuac son clasificadas de moderadamente duras ( $249 \mathrm{mg} / \mathrm{L})$ a muy duras $(1535 \mathrm{mg} / \mathrm{L})$ (EcuRed, 2017) dependiendo de la época. Cabe señalar que el lago que presentó la mayor dureza fue el 3 (gráfica 6). Valladares Rodríguez et al. (2016) determinaron en el lago Xico una dureza total $1453 \mathrm{mg} / \mathrm{L}$, semejante a lo registrado en el lago 3 que se encuentra frente a las áreas agrícolas donde se utilizan fertilizantes naturales como el $\mathrm{CaSO}_{4}$; por su parte, Barreiro Güemes (1997) estimó de 40 a 70 $\mathrm{mmol} / \mathrm{L}$ equivalente a 40 y $700 \mathrm{mg} / \mathrm{L}$ y Abeja Pineda et al. (2015) cuantificaron en Xochimilco un intervalo de 64 a $120 \mathrm{mg} / \mathrm{L}$, resultado del mismo origen. Desde el punto de vista químico, existen sales que pueden comprobarse a través de una simple correlación entre parámetros, es decir, que la dureza se relacione con la conductividad obteniéndose una correlación significativa $(r=0.591)$, lo que manifestó la presencia de $\mathrm{CaSO}_{4}$ (gráfica 5) o posiblemente $\mathrm{K}_{2} \mathrm{SO}_{4}$.

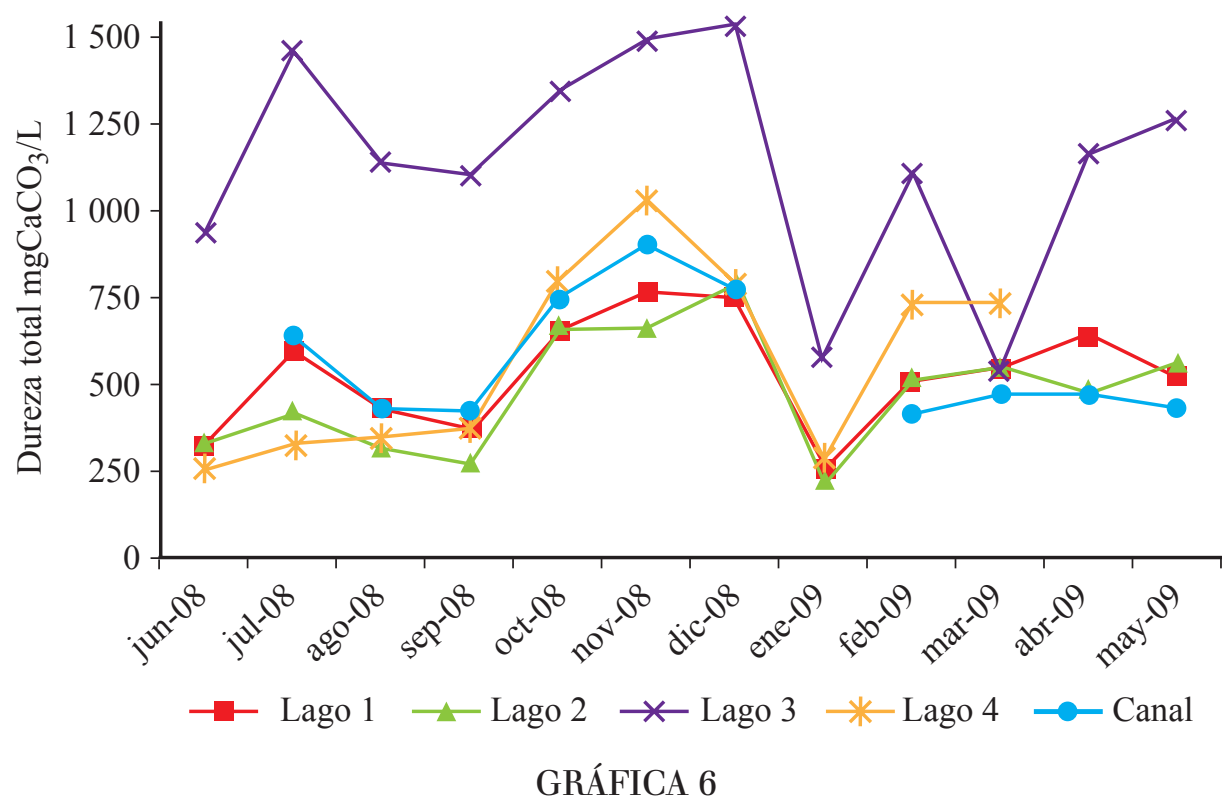

Variación mensual de dureza en cuatro lagos y el canal de la Ciénega de Tláhuac Fuente: elaboración propia. 


\section{7. Oxígeno disuelto y porciento de saturación}

En los cuatro lagos de la Ciénaga de Tláhuac las concentraciones de oxígeno disuelto variaron heterogéneamente en el espacio y el tiempo desde la anoxia la mayoría del tiempo hasta altos contenidos puntuales que superaron $100 \%$ de saturación, lo cual se intuye fue resultado de una alta actividad fotosintética en donde el fitoplancton está distribuido en parches, tal y como lo conceptúa Margalef (1983), que también puede ser aplicado a gases y sólidos suspendidos. En este sentido, Margalef (1983: 661) refiere en términos sucintos que

En el plancton, la movilidad propia de los organismos está negativamente correlacionada con el coeficiente de difusión turbulentala rigidez de la organización vertical cuando sólo hay organismos pequeños puede ser mayor que cuando existen peces y otros animales de gran movilidad y capacidad de transporte. El ecosistema de las aguas libres no se puede estudiar como si fuera un universo estadístico uniforme, sino que representa una organización anisotrópica, que aparece con propiedades diferentes según las direcciones en que se analice.

También puede deberse a la influencia de la circulación parcial del agua dependiente del viento que en la mayoría del tiempo de los muestreos fue en calma; debe incluirse una difusión química que, aunque lenta, ha sido continua por los asentamientos periféricos y superar a la influencia de los factores temperatura y salinidad en la concentración del gas.

Las condiciones hipóxicas pudieron ser resultado de la respiración y muerte del plancton con la consecuente degradación de su materia orgánica constitutiva. En su caso, los lagos 1 y 2 reciben descargas de aguas residuales y aguas aparentemente tratadas procedentes de la planta del Cerro de la Estrella (Barreiro Güemes, 1997), que también consumen este gas, el cual es considerado no conservativo por su alta reactividad química y biológica. En los meses de julio, agosto y septiembre, e incluso octubre, fueron de hipoxia hasta anoxia que se reflejó en el bajo porcentaje de saturación; en la estación 3 en marzo se determinaron elevadas concentraciones de oxígeno con una saturación hasta de $243.3 \%$ que se infiere sean resultantes de una alta actividad fotosintética, contrario al canal en donde las condiciones fueron en su mayoría anóxicas con una saturación deletérea o nociva para la vida acuática (gráfica 7 y gráfica 8). Barreiro Güemes (1997) refiere desde la década de los noventa, condiciones semejantes a este estudio realizado en 2008-2009, es decir, desde 1.4 a 7.5 mg/L; sin embargo, Ayala Pérez y Avilés Alatriste (1997) no mencionan condiciones de hipoxia o anoxia, posible resultado de la época, el año y sitio de muestreo.

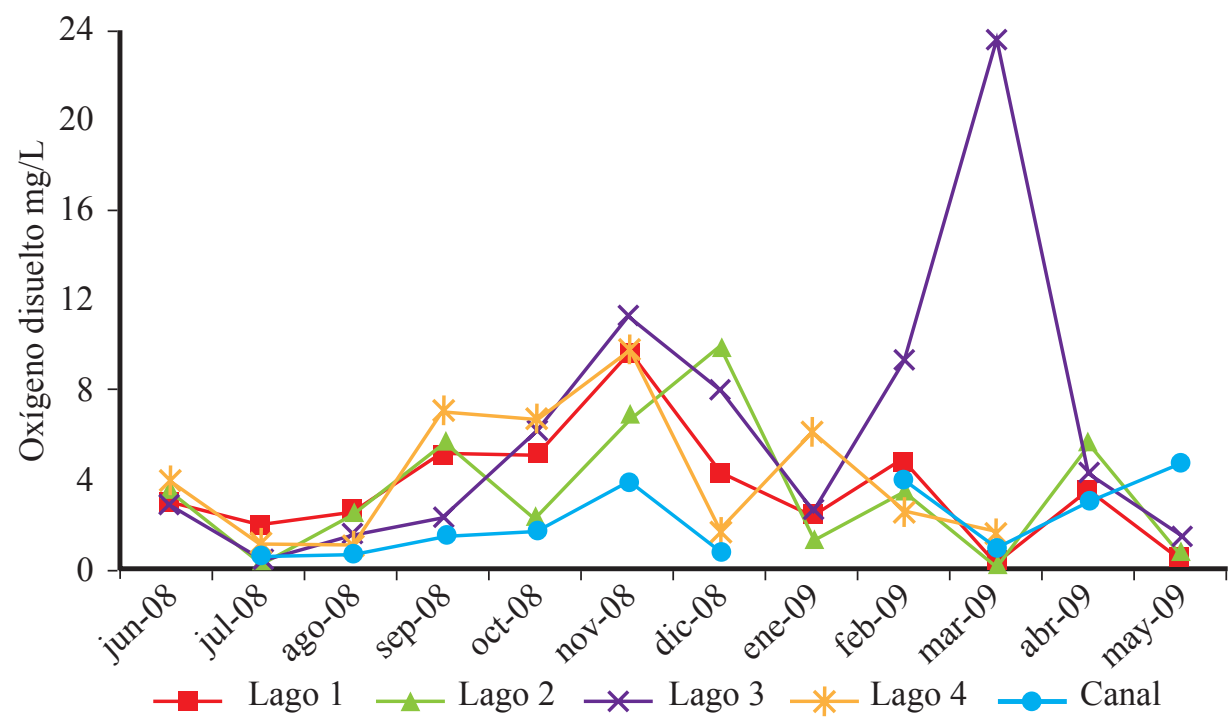

GRÁFICA 7

Variación mensual de oxígeno disuelto en cuatro lagos y canal de la Ciénega de Tláhuac Fuente: elaboración propia. 


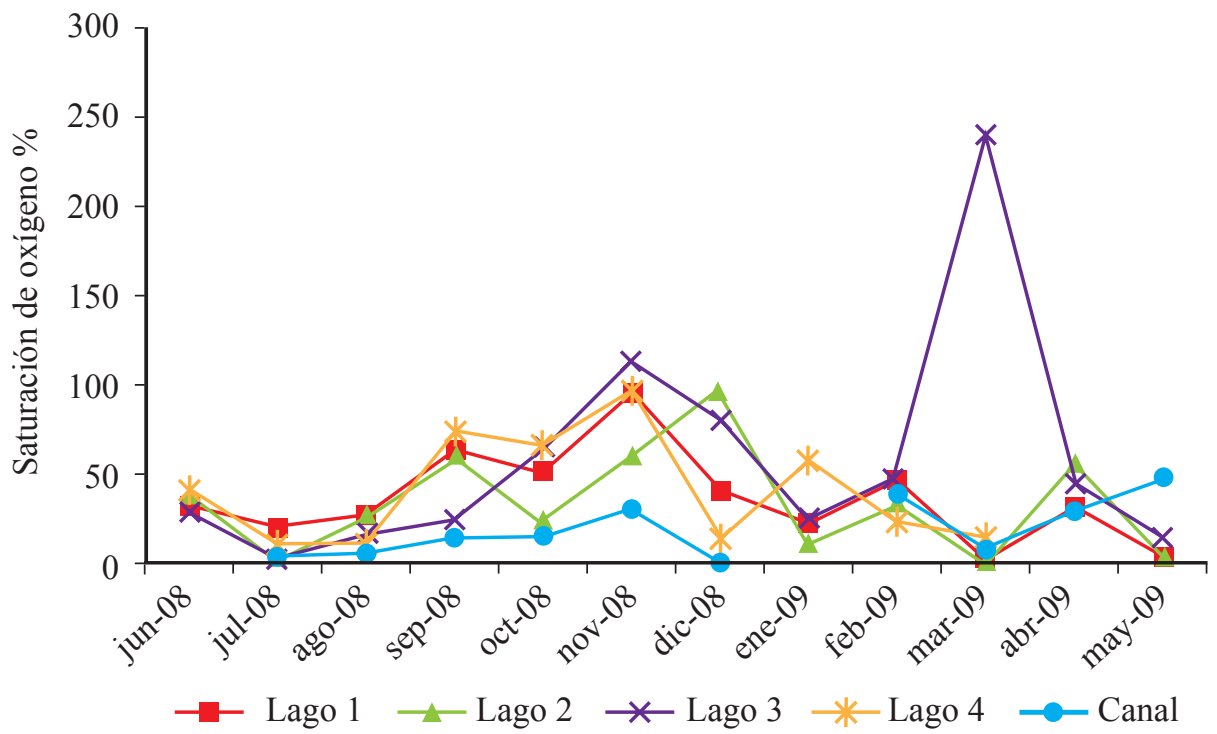

GRÁFICA 8

Variación mensual de saturación de oxígeno en cuatro lagos y canal de la Ciénega de Tláhuac Fuente: elaboración propia.

Este efecto de sobresaturación de oxígeno en el agua puede ser comparado y corroborado con el Lago Zimbabwe donde Marshall y Falconer (1973) calcularon hasta 180\%, el cual justificaron por una alta productividad primaria. Zambrano et al. (2009) con base en sus registros de temperatura y salinidad calcularon $135 \%$ de saturación en Xochimilco. Montaño Salazar (2010) en las esclusas de $1.5 \mathrm{~m}$ de profundidad del parque de la Alameda Oriente al este de la Ciudad de México estimó 150\% de saturación con $265 \mathrm{mg} / \mathrm{m}^{3}$ de clorofila. Lagunas Sánchez (2018) calculó en el lago de Chapultepec en la segunda sección poco más de 300\% de saturación de oxígeno. Olguín Flores (2018), por su parte, en los lagos del Bosque de Chapultepec estimó hasta 293\% en abril, resultado de una alta productividad primaria neta de $1781 \mathrm{mg} \mathrm{Cm}^{3} / \mathrm{h}$. En el lago viejo de Chapultepec Alcocer et al. (1988) señalan una elevada concentración de clorofila por encima de $800 \mathrm{mg} / \mathrm{m}^{3}$ debido al aporte externo de nutrientes, condición hipereutrófica. Es importante señalar que en los muestreos, entre las 12 y las 14 h los productores primarios deben estar fotosintetizando extraordinariamente; por lo tanto, esos valores de sobresaturación de OD no son sorprendentes en sistemas hipertróficos.

\section{8. Ortofosfatos y fósforo total}

En la Ciénega de Tláhuac se determinó un contenido heterogéneo alto de ortofosfatos en la mayoría de los muestreos (13.55 y $258 \mu \mathrm{M})$, especialmente en el lago $3(13.23$ y $354.84 \mu \mathrm{M})$, que definieron a la ciénega como hipereutrofizada (gráfica 9); dicho lago colinda con una densidad agrícola alta. Doce años antes Barreiro Güemes (1997), así como Ayala Pérez y Avilés Alatriste (1997), refirieron una concentración de ortofosfatos entre 16 a $255 \mu \mathrm{M}$, lo cual significó que desde la década de los noventa ya había una eutrofización considerada como natural. Verver y Vargas García (2005) cuantificaron en el Parque Tezozomoc amplios intervalos de 46 a 214 $\mu \mathrm{M}$, posteriormente Oliva Martínez et al. (2008) determinaron en un estudio anual niveles hasta de $106 \mu \mathrm{M}$ calificándolo como de condiciones ambientales en estado hipertrófico del lago; posteriormente, Montaño Salazar (2010) cuantificó niveles de $46 \mu \mathrm{M}$. En cuanto al fósforo total, en el 2008-2009 la ciénega tuvo una condición hipertrófica tomando como base la clasificación Moreno Franco et al. (2010) correspondiente a $24 \mu \mathrm{M}$, incluso la referida por Vollenweider y Kerekes (1982); destacó el lago 3 en noviembre (590 $\mu \mathrm{M})$ y un caso excepcional del lago 4 en marzo $(816 \mu \mathrm{M})$, como se ve en la gráfica 10 , que puede ser resultado de la ubicación puntual del 
muestreo, la época y tipo de cultivo circundante adyacente. Con base en Escobar Ruiz (2014) las descargas de asentamientos humanos tuvieron un contenido alto de fósforo total en Tláhuac.

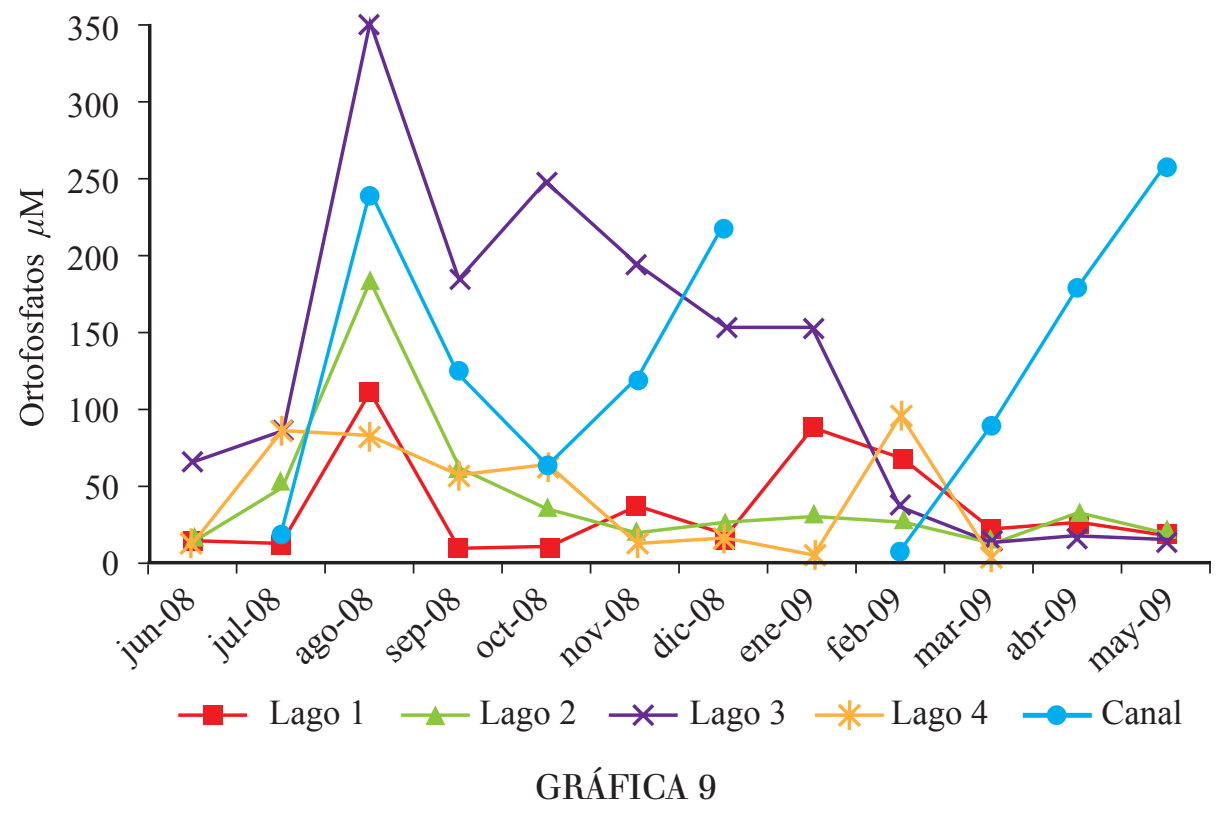

Variación mensual de ortofosfatos en cuatro lagos y canal de la Ciénega de Tláhuac Fuente: elaboración propia.

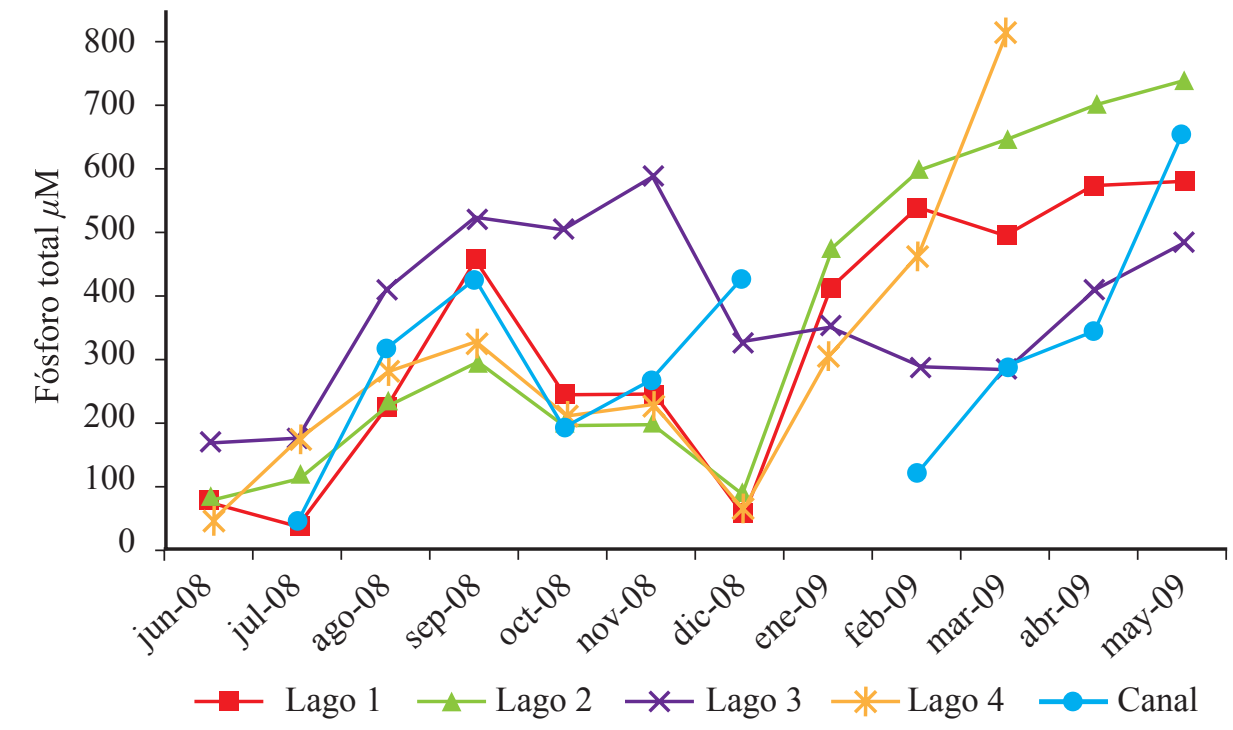

GRÁFICA 10

Variación mensual de fósforo total en cuatro lagos y canal de la Ciénega de Tláhuac

Fuente: elaboración propia.

\section{9. Amonio y nitrógeno total}

Las concentraciones de amonio en la Ciénaga de Tláhuac fueron muy variables en el espacio y en el tiempo. Los niveles más altos se presentaron en abril y mayo en los lagos 1 y 2 (564-464 $\mu \mathrm{M}$ respectivamente), al igual que en el lago 3 con una concentración excepcional en octubre $(692 \mu \mathrm{M})$; el lago 4 fue el que registró una 
disminución en todos los muestreos. Asimismo, en el canal se determinaron dos máximos que sobrepasaron las concentraciones de los lagos con contenidos de $3928 \mu \mathrm{M}$ (agosto 2008, mayo 2009). Las elevadas concentraciones de este ion se determinaron desde una visita prospectiva donde se observó la existencia de densos asentamientos urbanos que descargaban sus aguas residuales domésticas y además escurrimientos de campos agrícolas periféricos (mapa 1) que emplean fertilizantes como el sulfato de amonio, compuesto señalado por Navarro García y Navarro García (2014) que incrementa la concentración de este ion en el ambiente, como lo registraron Ayala Pérez y Avilés Alatriste (1997) en el lago 4. En el lago 1 se puede asociar a las aguas residuales del poblado asentado en la margen oeste y en el lago 2 por el inadecuado tratamiento de las aguas de la planta del Cerro de la Estrella (gráficas 11 y 12). En el caso del canal se puede atribuir a la fertilización intermitentemente de las hortalizas según la época del año (comunicación personal con un agricultor). Con base en la clasificación de Escobar Ruiz (2014), de acuerdo con las descargas de los pobladores, el contenido de amonio en Tláhuac fue alto.

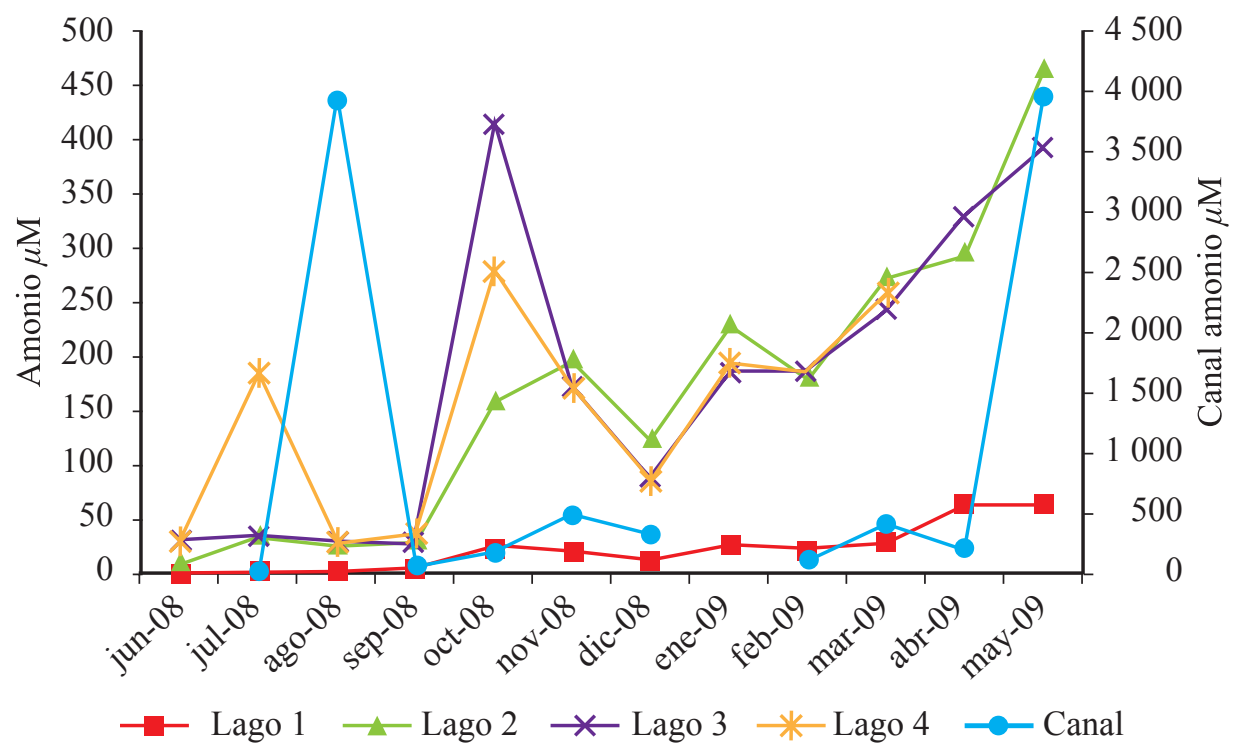

GRÁFICA 11

Variación mensual de amonio en cuatro lagos y canal de la Ciénega de Tláhuac Fuente: elaboración propia.

En el caso del nitrógeno total (NT), los contenidos en todos los cuerpos de agua de la Ciénaga fueron desde bajos $(128 \mu \mathrm{M})$ hasta extremadamente altos $(9000 \mu \mathrm{M})$. Dentro del NT le correspondió al amonio una concentración entre $43 \%$ y $13 \%$ del total e indican que son de descargas urbanas e inadecuado tratamiento de las aguas de descarga de la planta del Cerro de la Estrella.

Barreiro Güemes en su publicación de 1997 registró máximos de $14 \mu \mathrm{M}$ y Zambrano et al. en un informe del 2003 refirieron contenidos máximos de $429 \mu \mathrm{M}$ y mínimos de $214 \mu \mathrm{M}$ sugiriendo que los niveles eran demasiado tóxicos para permitir el establecimiento de alguna población acuática. En el lapso de 2008-2009 se incrementó el contenido de este ion en más de 14 veces el valor máximo referido por Barreiro Güemes (1997) y nueve veces el máximo señalado por Zambrano et al. (2003). Dadas las altas concentraciones de nitrógeno total registradas en este artículo, es posible que el incremento haya sido mucho mayor. En ambas formas del nitrógeno (orgánico e inorgánico) confirman la hipereutrofización tomando como base a Vollenweider y Kerekes (1982) y Moreno Franco et al. (2010). 
Según las altas concentraciones registradas de amonio y el pH alcalino de la Ciénega de Tláhuac, el amonio se transforma en amoniaco, gas tóxico para la vida acuática (State Water Resources Control Board, 2017), condición que no ha sido determinada en la ciénega.

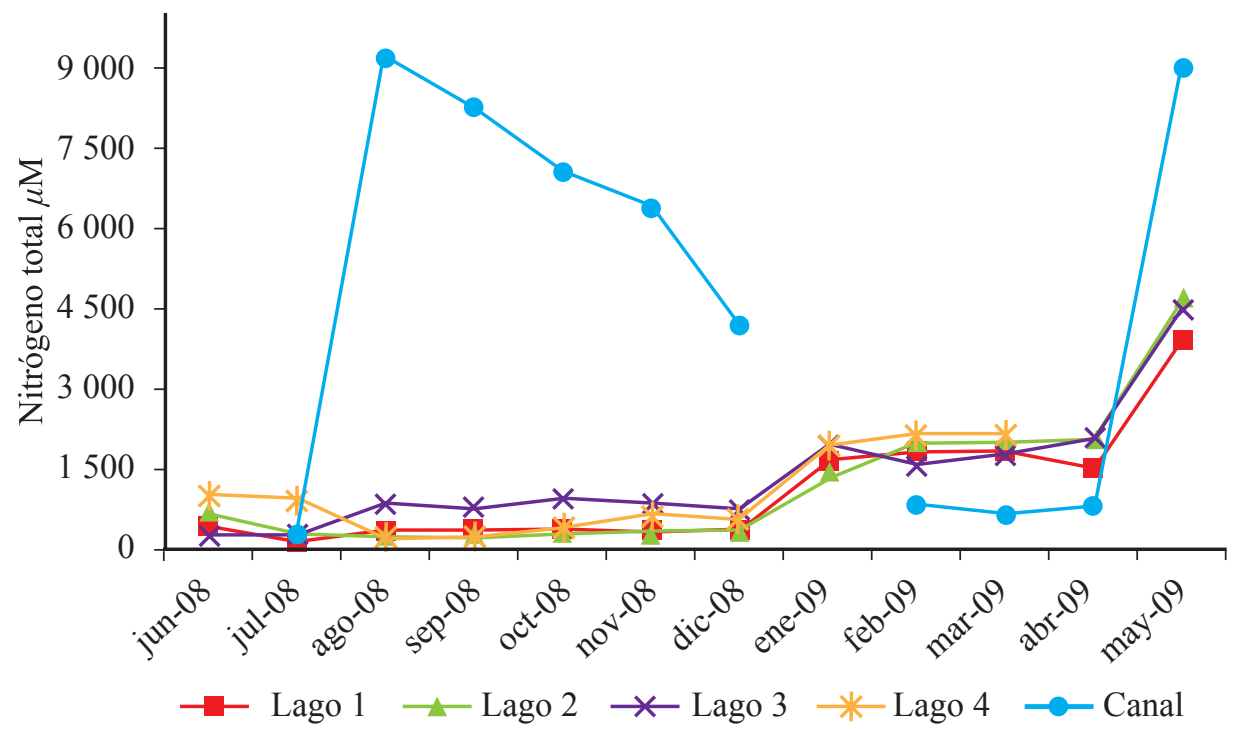

GRÁFICA 12

Variación mensual de nitrógeno total en cuatro lagos y canal de la Ciénega de Tláhuac Fuente: elaboración propia.

\section{10. Demanda química de oxígeno}

Este parámetro ha sido empleado para medir la calidad de aguas residuales o tratadas, pero también puede ser empleado para la estimación de la cantidad de materia orgánica producida autóctonamente (De la Lanza Espino et al., 2008). En los muestreos de la Ciénega de Tláhuac se empleó fundamentalmente para estimar su carga orgánica degradable, procedente de fuentes naturales (fitoplancton, vegetación sumergida, excretas de aves y peces), a pesar de que se haya incluido también la carga orgánica de los asentamientos humanos y sus actividades agropecuarias periféricas. Con base en esto, la mayoría los lagos sobrepasaron los niveles máximos permisibles (100-120 mg/L) propuestos por las Normas Técnicas Ecológicas (1992) de la Secretaría de Agricultura y Recursos Hidráulica, Comisión Nacional del Agua e Instituto Mexicano de Tecnología del Agua, aunque no se refiera en específico a que categoría le corresponde la ciénega en este trabajo. La variación en los meses de lluvia (de junio a septiembre) fueron concentraciones bajas y el resto del año sobrepasaron los niveles máximos señalados (gráfica 13); sin embargo, tomando en cuenta la clasificación de Escobar Ruiz (2014) a la ciénega le correspondería una DQO de baja a media. En el caso del canal los resultados fueron heterogéneos con mínimos y máximos, resultado del cultivo intermitente de hortalizas. Según la FAO (2017), la manipulación de las hortalizas, en particular de su lavado con aguas superficiales contaminadas con materiales orgánicos, plaguicidas entre otros, práctica común en muchos países en desarrollo, da lugar a la contaminación de los cultivos y alimentos, por lo que se recomiendan técnicas para la determinación de la DQO; no obstante, en la Ciénega de Tláhuac no se llevan a cabo ninguna técnica para determinar la calidad del agua para el riego de las hortalizas.

Dado que la DQO cuantifica la cantidad de oxígeno requerida para oxidar la materia orgánica, tiene importancia desde el punto de vista ecológico, ya que altos niveles de la DQO manifiestan indirectamente condiciones tendientes a la hipoxia o anoxia, que en el caso de la ciénega el riesgo es para la fauna acuática. 


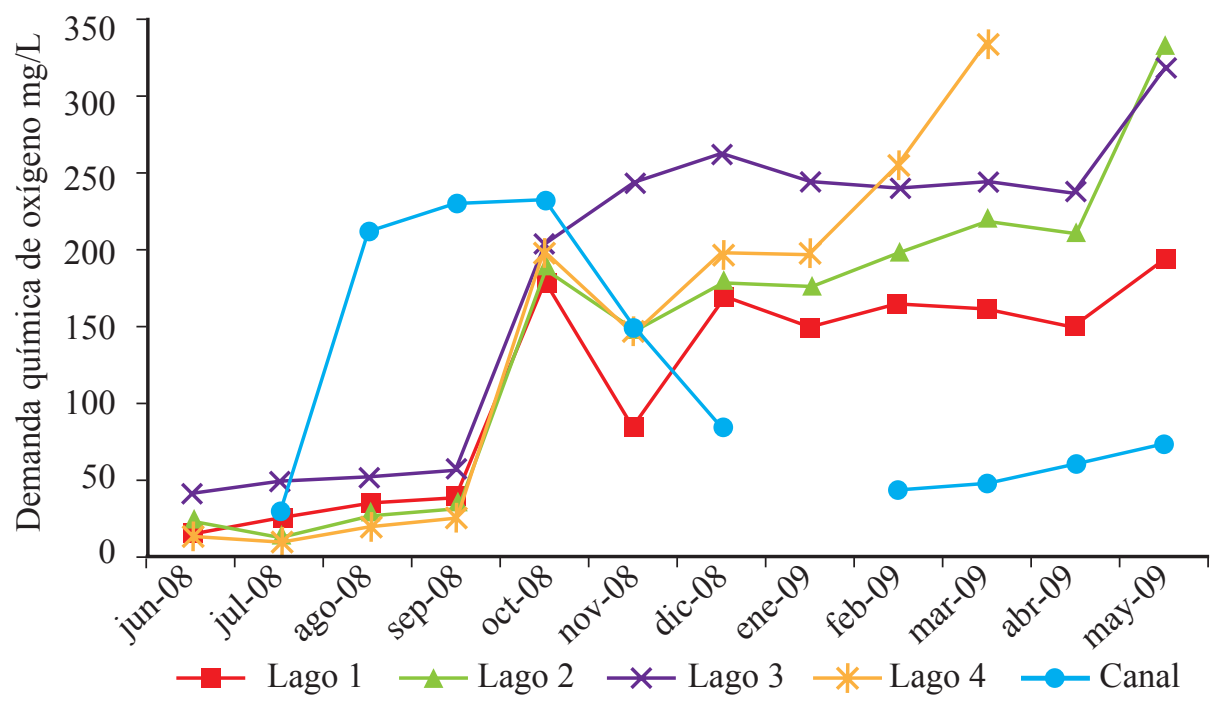

GRÁFICA 13

Variación mensual de demanda química de oxígeno en cuatro lagos y canal de la Ciénega de Tláhuac Fuente: elaboración propia.

\section{11. Sustancias activas al azul de metileno (detergentes)}

Con el objetivo de asociar otros compuestos que contengan fósforo se deben considerar las descargas con detergentes, lo cual correspondería no solamente a la calidad del agua sino también al ambiente ecológico. A la fecha la Norma Oficial Mexicana NOM-001-ECOL-1996 no incluye límites permisibles de detergentes; no obstante, el Reglamento de los Servicios de Agua Potable, Alcantarillado y Saneamiento para el Municipio de León, Guanajuato (2010) propone como límite $15 \mathrm{mg} / \mathrm{L}$, los cuales no se rebasaron en los cuatro lagos de la Ciénaga de Tláhuac. Los niveles más altos se registraron en los meses de lluvia (junio, julio y agosto) (gráfica 14), donde hay mayores escurrimientos fluviales mezclados con descargas residuales y como señala Bazant (2017) entre más agua de consumo habrá mayores volúmenes de aguas residuales y por consecuencia mayor contaminación no solamente superficial sino en los sedimentos que por desadsorción se liberan aquellos que quedaron retenidos (gráfica 14)



Variación mensual de sustancias activas al azul de metileno (SAAM) en cuatro lagos y canal de la Ciénega de Tláhuac Fuente: elaboración propia. 


\section{12. Coliformes totales y fecales}

A pesar de que fue un objetivo secundario, al estimar el origen del agua en la ciénega se incluyó la bacteriología asociada a asentamientos humanos y sus descargas. Se registraron coliformes totales en los cuatro lagos, incluyendo el canal, con contenidos por arriba de la Norma Oficial Mexicana NOM-001-ECOL-1996, aunque con un comportamiento heterogéneo, en particular en el lago 1 (descargas residuales del poblado adyacente) con más de $50000 \mathrm{NMP} / 100 \mathrm{ml}$ de coliformes totales y $25000 \mathrm{NMP} / 100 \mathrm{ml}$ de coliformes fecales (gráfica 15 y gráfica 16), lo cual significó la influencia de aguas negras vertidas directamente o las mal tratadas procedentes de la planta del Cerro de la Estrella. Lo anterior sugiere que las aguas de la Ciénaga de Tláhuac no son aptas para el humano, para recreación ni para la vida silvestre. Según la clasificación de Escobar Ruiz (2014), en las descargas de poblados

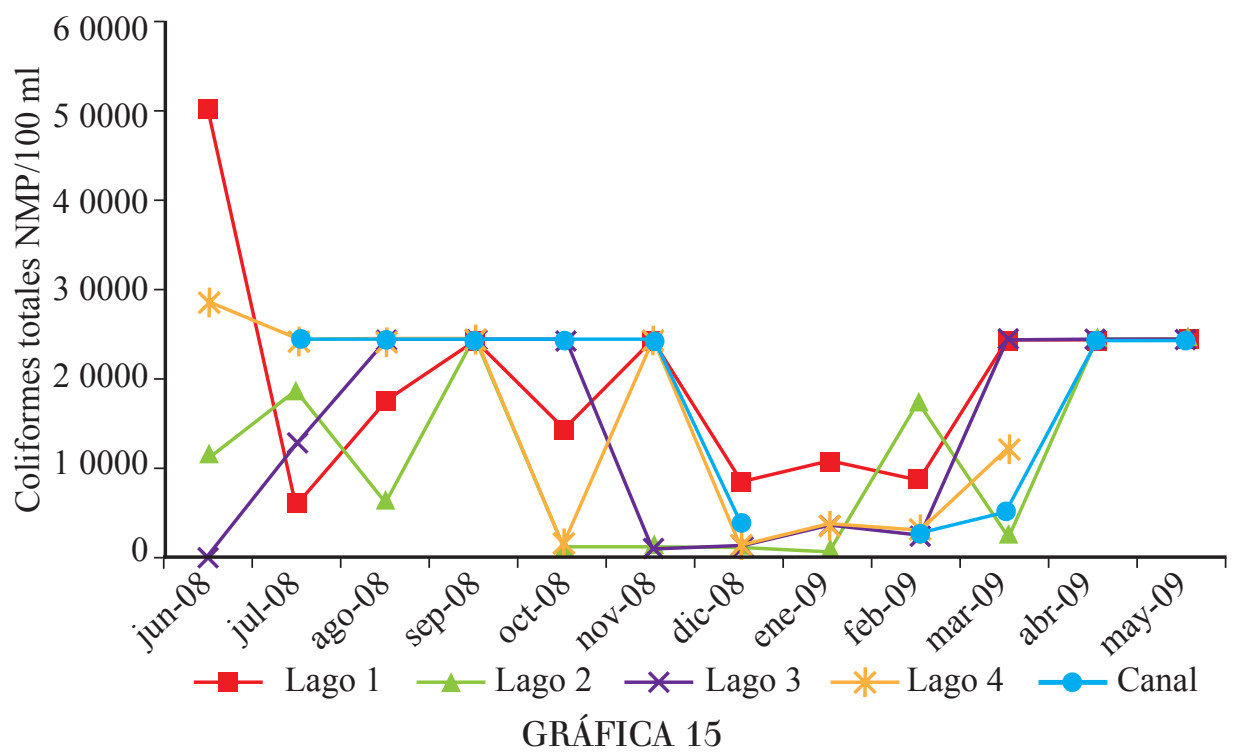

Variación mensual de coliformes totales en cuatro lagos y canal de la Ciénega de Tláhuac Fuente: elaboración propia.

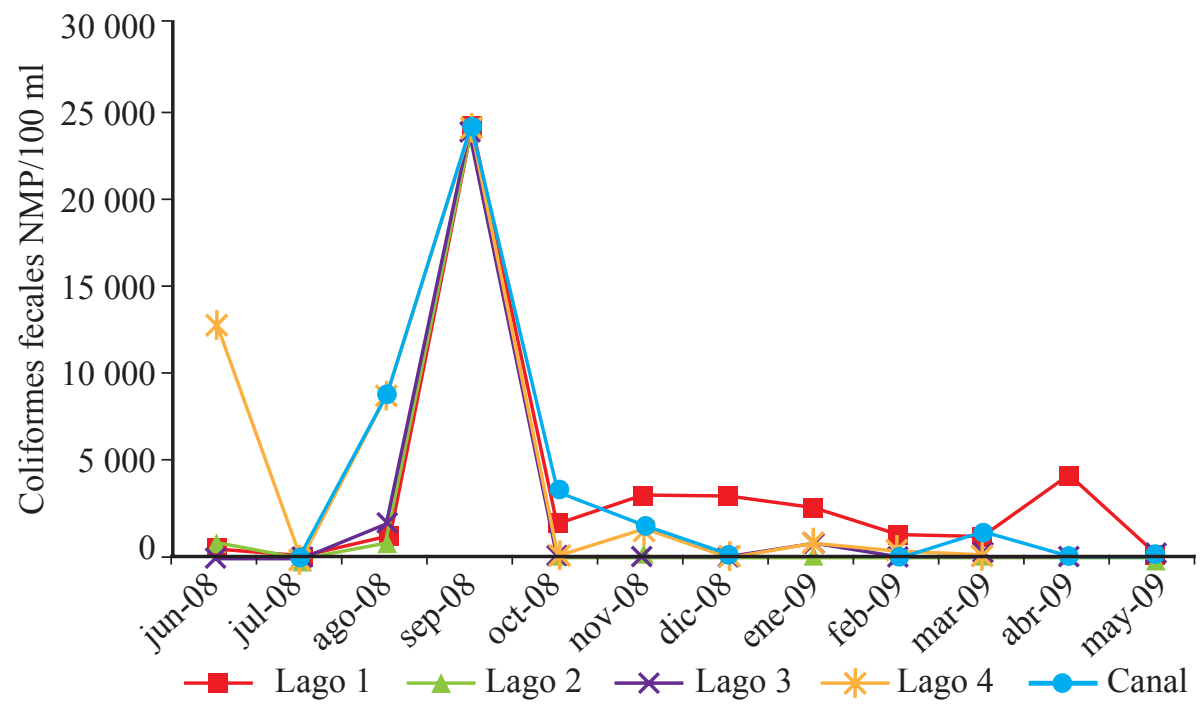

GRÁFICA 16

Variación mensual de coliformes fecales en cuatro lagos y canal de la Ciénega de Tláhuac Fuente: elaboración propia. 
el contenido de coliformes totales fue bajo. Ayala Pérez y Avilés Alatriste (1997) registraron coliformes totales variables entre $35129 \mathrm{NMP} / 100 \mathrm{~mL}$ a $716 \mathrm{NMP} / 100 \mathrm{~m}$ de acuerdo con la ubicación de los sitios muestreados.

\section{13. Metales traza}

El sodio, potasio, calcio y magnesio mostraron sus mayores concentraciones en el lago 3 que coincidieron con los mayores niveles de sulfatos y dureza, por lo que las sales predominantes pueden ser los sulfatos de calcio y magnesio; bajo etas consideraciones, el agua de la ciénega pudiera ser clasificada como de dureza permanente que desde el punto de vista de consumo humano pueden existir ciertos problemas en el sistema nervioso y pulmonar, además perjudiciales para el medio ambiente en general (ECOagricultor, 2017). A pesar de que el sodio es un elemento que juega un papel importante en el mantenimiento de la permeabilidad de los suelos por irrigación cuando se encuentra en forma de sulfato de sodio en el agua no es recomendable para la agricultura. De considerarse la formación de dicha sal, estaría presente en la mayoría de los lagos y particularmente en el 3 de acuerdo con la NOM-002 SEMARNAT-1996.

En relación con los metales, mercurio, plomo, cromo, cadmio, manganeso y zinc se encontraron en niveles traza y menores a $25 \mathrm{ng} / \mathrm{mL}$. Cabe destacar que los contenidos de arsénico fueron de bajo a mediano en particular en el lago 3, donde se determinó en un primer análisis $0.1 \mathrm{mg} / \mathrm{L}$ que con base en la NOM-003-SEMARNAT-1996 se encuentra por debajo del límite establecido en descargas de aguas residuales a los sistemas de alcantarillado urbano. En la última determinación de estos metales traza se confirmó que no representan riesgo alguno para el ecosistema, agricultura o a la salud humana.

\section{AnÁlisis PROSPECTIVo}

El conocimiento y comprensión de los cuerpos de agua lóticos y lénticos no sólo debe considerar que el preciado líquido forma parte de un ciclo local e incluso mundial dentro del clima, sino que también es responsable de la diversidad de ecosistemas. En este sentido, conforme crecen las poblaciones humanas y se diversifican sus actividades, se genera un desequilibrio entre el ambiente y el desarrollo poblacional, lo que resulta en pérdidas de cuerpos de agua y por lo tanto de la riqueza biológica en flora y fauna locales y migratorias que pueden llegar a su desaparición también. Para tratar de resolver dicha inequidad adecuadamente es necesario contar con estudios históricos ambientales del comportamiento acuático natural y el inducido por el hombre que no siempre se tienen; asimismo, impulsar su continuidad, situación que no se realiza debido no sólo al poco interés sino a la creencia que el recurso agua es inagotable y dirigido nada más a las necesidades antropogénicas sin considerar a los recursos vivos. Un ejemplo de lo anterior, además de muchos otros, es la Ciénega de Tláhuac en el Estado de México, importante históricamente porque formaba parte de la gran Cuenca de México que incluía varios cuerpos de agua, entre ellos Chalco, y se intercomunicaba con la ciénega resultando en un ecosistema único que dio lugar a la creación de las chinampas, tipo de cultivo utilizado por los aztecas antes del siglo XV, y manejado según los historiadores en forma equilibrada al ambiente. Desde entonces la actividad agrícola continuó hasta la fecha; sin embargo, esta actividad expansiva fue modificando la morfología e incluso la calidad del agua que incide también en la biodiversidad. No existe un seguimiento sobre la calidad del agua y sus recursos biológicos y es hasta la década de los noventa cuando se iniciaron estudios con enfoque ambiental, pero con escasa continuidad, una situación que no permite definir la evolución de la ciénega para un manejo adecuado no sólo ambiental sino de conservación y de administración. Lo que se ha encontrado hasta 2009 es un gran deterioro resultado de la falta de planeación en el crecimiento en los asentamientos humanos y sus actividades adyacentes a la ciénega, pues continúa el desinterés y no se atienden las recomendaciones que han propuesto académicos anteriores. Con base en esto último, es recomendable la continuación de los estudios, no únicamente para definir la interacción entre el hombre con su actividad incontrolada y el ambiente sino también ante el cambio climático. 


\section{Conclusiones}

Por su naturaleza y origen geomorfológico, los cuatro lagos que conforman la Ciénega de Tláhuac contienen aguas entre semiduras a duras, además alcalinas, con concentraciones heterogéneas de oxígeno, desde sobresaturaciones puntuales de $>$ de $250 \%$, posible resultado de una alta actividad fotosintética, hasta la hipoxia que fue más generalizada; con altos contenidos de nutrientes y materia orgánica al grado de la hipereutrofización que hacen de ello un agua de condiciones ambientales extremas solamente apropiadas para aquellos organismos tolerantes o adaptativos. Dichas características fisicoquímicas o de calidad del agua no nada más son resultado de un cuerpo de agua léntico, de baja profundidad y escasa mezcla sino también de las descargas antropogénicas y actividades agrícolas periféricas definidas en forma presencial y que además han ido en incremento por el desarrollo demográfico y sus necesidades, en especial en un periodo de más de dos décadas; en ese lapso ha pasado de un ambiente de eutrófico a hipertrófico que pudiera ser mitigado evitando las descargas urbanas sin tratamiento adecuado y las agrícolas como fue recomendado hace 20 años para una posible rehabilitación. Al no contar con un sistema de tratamiento de las aguas de descarga urbanas eficiente, ya se han registrado bacterias entéricas (coliformes fecales) que ponen en riesgo a la flora y la fauna e incluso al hombre. A pesar de lo anterior, la Ciénega de Tláhuac sigue sosteniendo una avifauna significativa local y migratoria, motivo por lo cual ha sido considerada como área protegida en la que se incluyen especies endémicas en peligro de extinción, e indicar que deben tomarse medidas conservacionistas tanto para el medioambiente, mejoramiento de la calidad del agua y sanitarias como el control de las descargas de aguas residuales o hacer un método efectivo en las plantas de tratamiento que desde hace dos décadas fueron propuestas por otros autores y no han sido aplicadas, resultado de una falta de planeación entre el crecimiento poblacional y la conservación ecológica de los recursos acuáticos.

\section{REFERENCIAS}

Abeja Pineda, O., López López, E., Favari, L., \& Sedeño Díaz, J. E. (2015). Algal growth potential and oxidative stress in Ankistrodesmus falcatus exposed to waters from Xochimilco lake system, Mexico. Aquatic Ecosystem Health and Management, 18(2), 221-231.

Alcántara, J. L., \& Escalante Pliego, P. (2005). Current threats to the Lake Texcoco globally important bird area. USDA Forest Service General Technical Report. PSW-GTR-191, 1143-1150.

Alcocer, J., Kato, E., Robles, E., \& Vilaclara, G. (1988). Estudio preliminar del efecto del dragado sobre el estado trófico del Lago Viejo de Chapultepec. Revista Internacional de Contaminación Ambiental, 4(1), 43-56.

APHA (American Public Health Association). (1995). Standard methods for the examination for water and wastewater (19th edition). Washington, D. C.: Byrd Pre Springfield.

Arriaga, C. L., Aguilar, V. y Alcocer, J. (2000). Aguas continentales y diversidad biológica de México. México: CONABIO.

Ayala Pérez, L. A. y Avilés Alatriste, O. A. (1997). Calidad del agua y concentración de nutrientes, en M. T. Barreiro Güemes, R. Sánchez-Trejo, A. Aguirre-León y L. M. Ayala-Pérez (Eds.), Ecología del humedal de San Pedro Tlábuac: un sistema lacustre del Valle de México (pp. 31-41). México: Universidad Autónoma Metropolitana-Xochimilco.

Ayala Pérez, V., Arce, N. y Carmona, R. (2013). Distribución espacio-temporal de aves acuáticas invernantes en la Ciénega de Tláhuac, planicie lacustre de Chalco, México. Revista Mexicana de Biodiversidad, 84, 327 337. https://10.7550/rmb.28632.

Barreiro Güemes, M. T. (1997). Ecología del humedal de San Pedro Tlábuac: un sistema lacustre del Valle de México. México: Universidad Autónoma Metropolitana-Xochimilco. 
Barreiro Güemes, M. T., Sánchez-Trejo, R., Aguirre-León, A. y Ayala-Pérez, L. A. (1997). Ecología del humedal de San Pedro Tláhuac: un sistema lacustre del Valle de México. México: Universidad Autónoma MetropolitanaXochimilco.

Barreiro Güemes, M. T. (1998). Caracterización ecológica de los cuerpos de agua de Tláhuac, D.F., en M. Barreiro Güemes y R. Sánchez Trejo (Eds.), Recuperación integral de cuerpos de agua del Distrito Federal. Departamento El Hombre y su Ambiente. México: Universidad Autónoma Metropolitana Unidad Xochimilco (pp. 57-112).

Bazant, J. (2017). Hacia un desarrollo urbano sustentable. Incremento de volúmenes de aguas residuales en la época delluvias. Consultado en octubre de 2017. Disponible en https://books.google.com.mx/books

Botello, A. y Villanueva, S. (2017). Plásticos en los océanos. Instituto de Ciencias del Mar y Limnología.

CONABIO (2017a). Remanentes del complejo lacustre de la cuenca de México. México. Consultado en enero de 2017. Disponible en http://www.conabio.gob.mx/conocimiento/regionalizacion/doctos/ rhp_068.html.

CONABIO (2017b). Ciénega de Tlábuac. México. Consultado en enero de 2017. Disponible en http:// conabioweb.conabio.gob.mx/aicas/doctos/C-73.html.

De la Lanza Espino, G., Alcocer Durand, J., Moreno Ruiz, J. L. y Hernández Pulido, S. (2008). Análisis químico-biológico para determinar el estatus trófico de la Laguna de Tres Palos, Guerrero, México. Hidrobiológica, 18(1), 21-30.

ECOagricultor. (2017). Efectos de los metales pesados en la salud y cómo eliminarlos. Consultado en octubre de 2017. Disponible en https://www.ecoagricultor.com/los-efectos-de-los-metales-pesados-en-la-salud-ycomo-eliminarlos/

EcuRed. (2017). Disponible en https://www.ecured.cu/Premio_LATINATEC

Escobar Ruiz, V. (2014). Análisis instrumental de la variabilidad climática y de la calidad del agua en plantas de tratamiento de agua residual. Caso de Estudio (tesis). México: Universidad Nacional Autónoma de México.

FAO (Food and Agriculture Organization). (1997). Contaminación agrícola de los recursos hídricos. Consultado en octubre de 2017. Disponible en http://www.fao.org/docrep/W2598S/w2598s03.htm

Fink, A. (1988). Fertilizantes y fertilización. Fundamentos y métodos para la fertilización de cultivos. Barcelona: Editorial Reverté, S. A.

García, E. (1973). Modificaciones al sistema de clasificación climática de Köppen (segunda edición). México: UNAM.

García Calderón, J. L. y De la Lanza Espino, G. (1995). La Cuenca de México, en G. de la Lanza-Espino y J. L. García-Calderón (Comps.), Lagos y presas de México (pp. 27-50). México: Centro de Ecología y Desarrollo, A. C.

Lagunas Sánchez, M. Y. (2018). Lagos de Chapultepec: metabolismo lacustre (tesis de maestría). México: UNAM.

Luna Pabello, V. y Aburto Castañeda, S. (2014). Sistema de humedales artificiales para el control de la eutrofización del lago del bosque de San Juan de Aragón. Ciencias Bioquímicas, 17, 12-55.

Margalef, R. (1983). Limnología. Barcelona: Ediciones Omega.

Marshall, B. E. y Falconer, A. C. (1973). Eutrophication of a tropical African impoudment (Lahe McIlwaine). Hidrobiología, 43(1-2), 109-123.

Martínez Vidal, J. L., González Rodríguez, M. J., Belmonte Vega, A. y Garriso Frenich, A. (2004). Estudio de la contaminación por pesticidas en aguas ambientales de la provincia de Almería. Ecosistemas, Asociación Española de Ecología Terrestre, Alicante España, 13(3), 1-10 
Meléndez Herrada, A. y Binnqüist Cervantes, G. (1997). Comunidad ornitológica, en M. T. Barreiro Güemes, R. A. Sánchez-Trejo, A. Aguirre-León y L. M. Ayala-Pérez (Eds.), Ecología del humedal de San Pedro Tlábuac: un sistema lacustre del Valle de México (pp.71-86). México: Universidad Autónoma MetropolitanaXochimilco.

Montaño Salazar, I. (2010). Aspectos hidrobiológicos en dos esclusas del lago artificial del parque de la alameda oriente (tesis de licenciatura). México: FES Zaragoza, UNAM.

Moreno Franco, D. P., Quintero Manzano, J. y López Cuevas, A. (2010). Métodos para identificar, diagnosticar y evaluar el grado de eutrofia. Contactos, 78, 25-33.

Nandini, S., Ramírez-García, P., \& Sarma, S. (2016). Water quality indicators in Lake Xochimilco, Mexico. Zooplankton and Vibio cholerae Journal of Limnology, 75(1), 91-100.

Navarro García, G. y Navarro García, S. (2014). Fertilizantes: quimica y acción. España: Ediciones Mundi-Prensa.

Norma Oficial Mexicana NOM-001-ECOL-1996. (1996). Que establece los límites máximos permisibles de contaminantes en las descargas de aguas residuales en aguasy bienes nacionales. México. Disponible en http:// dof.gob.mx/nota_detalle.php?codigo $=4863829 \&$ fecha $=06 / 01 / 1997$

Norma Oficial Mexicana NOM-002-ECOL-1996. (1996). Que establece los límites máximos permisibles de contaminantes en las descargas de aguas residuales a los sistemas de alcantarillado urbano o municipal. México. Disponible en http://dof.gob.mx/nota_detalle.php?codigo=4881304\&fecha=03/06/1998

Norma Oficial Mexicana NOM-003-ECOL-1996. (1996). Que establece los límites máximos permisibles de contaminantes para las aguas residuales tratadas que se reúnen en servicios al público. México. Disponible en http://www.ordenjuridico.gob.mx/Documentos/Federal/wo69207.pdf

Norma Oficial Mexicana NOM-059-SEMARNAT-2010. (2010). Protección ambiental-Especies nativas de México de flora y fauna silvestres-Categorias de riesgo y especificaciones para su inclusión, exclusión o cambio-Lista de especies en riesgo. México. Disponible www.profepa.gob.mx/innovaportal/file/435/1/NOM_059_ SEMARNAT_2010.pdf

Normas Técnicas Ecológicas. (1992). Diario Oficial de la Federación. México: SARH, CNA, IMTA.

Olguín Flores, Z. M. (2018). Variación espacial y temporal de la producción primaria en los Lagos de Chapultepec, Ciudad de México (tesis de licenciatura). México: UNAM.

Oliva Martínez, M. G., Rodríguez Rocha, A., Lugo Vázquez, A. y Sánchez Rodríguez, M. R. (2008). Composición y dinámica del fitoplancton en un lago urbano hipertrófico. Hidrobiológica, 18(1, Supl. 1), 1-13.

Ortiz Zamora, D. y Ortega Guerrero, M. A. (2007). Origen y evolución de un nuevo lago en la planicie de Chalco: implicaciones de peligro por subsidencia e inundación de áreas urbanas en Valle de Chalco (Estado de México) y Tláhuac (Distrito Federal). Investigaciones Geográficas Boletín del Instituto de Geografía UNAM. 64, 26-42.

PAOT (Procuraduría Ambiental y de Ordenamiento Territorial). (2008). Estudio sobre la zona chinampera y demás afectadas de las delegaciones Xochimilco, Tlábuac y milpa alta, por la proliferación de asentamientos humanos irregulares en materia de afectaciones al medio ambiente y el ordenamiento territorial. México: Subprocuraduría de Ordenamiento Territorial, Dirección de Estudios, Dictámenes y Peritajes del Ordenamiento Territorial.

Reglamento de los Servicios de Agua Potable, Alcantarillado y Saneamiento para el Municipio de León, Guanajuato. (2010). Periódico Oficial del Gobierno del Estado año XCVII, Tomo CXLVIII, Guanajuato, Guanajuato, 21, México.

Sánchez, H. A. (2004). Algunas aplicaciones de oleoquímica en jabones y detergentes. Palmas (número especial, tomo I), 382-400. 
Sandoval, R. P., Gajardo, S. S., Benites, V. J. y López, V.J. (2014). Utilización de sulfato de cobre para la elaboración de un jabón líquido antiséptico. Revista Cubana de Farmacia, 48(4), 542-549.

State Water Resources Control Board (2017). Consultado en octubre 2017. Disponible en https://www. waterboards.ca.gov/water_issues/programs/swamp/docs/.../3310sp.pdf

UNESCO-México (2006). Organización de las Naciones Unidas para la Educación la Ciencia y la Cultura. Xochimilco: un proceso de gestión participativa.

Valladares Rodríguez, M. R., Flores Valverde, E. y García Zúñiga, A. J. (2016). Propuesta de tratamiento del agua del Lago Xico, en N. Ríos, G. Dévora y D. Encinas (Comp.), Memorias del 3er. Congreso Nacional de Tecnologías y Ciencias Ambientales. Séptimo Congreso Regional de Ciencias Ambientales (pp. 22). México: ITSON, Universidad Autónoma Metropolitana Unidad Azcapotzalco.

Verver y Vargas García, J. (2005). Dinámica espacio-temporal de los parámetros físicos y químicos y su relación con la clorofila a en un lago urbano eutrófico (tesis de licenciatura). México: UNAM.

Vollenweider, R. A., \& Kerekes, J. (1982). Eutrophication of waters, monitoring, assessment and control. Final report OECD Cooperative program on monitoring of inland waters (Eutrophication control), Environment Directorate, OECD. Paris.

Zambrano, L., Reynoso, V. H. y Herrera, G. (2003). Abundancia y estructura poblacional del axolotl (Ambystoma mexicanum) en los sistemas dulceacuicolas de Xochimilco y Chalco. México: Universidad Nacional Autónoma de México. SNIBCONABIO Proyecto AS004. México.

Zambrano, L., Contreras V., Mazari Hiriart, M., \& Zarco Arista, A. (2009). Spatial heterogeinity of water quality in a highly degraded tropical freshwater ecosystem. Enviromental Management, 43, 249-263.

\section{Notas}

[1] Disponible en http://www.pronatura.org.mx/news05humedal-tlahuac/. Consultado en enero de 2017.

\section{BY-NC-ND}

